\title{
Para além do espaço verde na escola: análise das concepções sobre educação ambiental vinculadas à proposta da Mostra de Educação Ambiental no Ceará
}

\section{Beyond green spaces in school: analysis of conceptions about environmental education linked to the exhibition of environmental education's purpose in Ceará}

\author{
Diego Adaylano Monteiro Rodrigues ${ }^{1}$. Raquel Crosara Maia Leite ${ }^{1}$
}

\begin{abstract}
Resumo: Neste trabalho, definimos como objetivo identificar e discutir as concepções sobre educação ambiental presentes na proposta da Mostra de Educação Ambiental da Rede Estadual de Ensino (MEA), no Ceará. Assumimos o paradigma qualitativo de investigação e realizamos entrevistas com organizadores do evento, que também são formadores ambientais responsáveis pela educação ambiental (EA) no Estado do Ceará. Após esta etapa, relacionamos os dados das entrevistas com a pesquisa documental sobre os editais do evento. Fundamentados pela Análise de Conteúdo, analisamos os temas, palavras e expressões que se aproximam ou se distanciam das perspectivas sobre EA descritas na literatura. Consideramos que a proposta da MEA apresenta diferentes perspectivas da EA, tais como inserções conservacionistas, científicas, resolutivas e críticas. Está presente no horizonte pedagógico deste evento a busca de projetos que fazem transformações sociais e curriculares.
\end{abstract}

Palavras-chave: Educação ambiental. Concepções. Mostras ambientais.

\begin{abstract}
In this work, we set our goal to identify and discuss the conceptions about environmental education, which are present in the aims of the Exhibition of Environmental Education of the State Teaching Network in Ceará (MEA). We employed a qualitative investigation paradigm and surveyed the event organizers, who are also environmental education (EA) teachers in the state of Ceará. After this initial phase, we matched the survey's data with the documented data from the event notices. Based on Content Analysis, we analysed themes, words and expressions that are either close or distant from the EA perspectives described in the literature. We considered that MEA's purpose presents different EA perspectives such as conservationist, scientific, vigorous and critical ideas. Additionally, the search for projects that make social and curricular transformations is present in this event's pedagogic scope.
\end{abstract}

Keywords: Environmental education. Environmental exhibition. Conceptions.

\footnotetext{
${ }^{1}$ Universidade Federal do Ceará (UFC), Fortaleza, CE, Brasil. E-mail: < diegoadaylano@gmail.com>.
} 


\section{Introdução}

A expressão educação ambiental (EA) ganhou notoriedade nos anos 60. Em sua gênese histórica, Dias (2004) aponta que ela foi concebida como uma educação voltada aos cidadãos, mas sua essência era vista como uma ecologia ou biologia degenerada, simplificada para tratar sobre o meio ambiente. Contudo, essa percepção sobre EA modificou-se, após a Conferência de Tbilisi $(1977)^{2}$, que recomendou uma visão integral do meio ambiente, por intermédio de diferentes campos do conhecimento que não restringem a educação ambiental à ecologia aplicada.

Nessas cinco décadas de desenvolvimento da EA e sua inserção no campo educacional, existe uma representação diversificada que pode ser chamada de correntes, identidades e macrotendências da EA. Guimarães (2004) faz a distinção da EA crítica em contraposição à EA conservadora, isto é, esta última busca reproduzir os interesses dominantes e paradigmas que balizam a sociedade moderna. Para esse autor, a ação educativa da EA conservadora se implementa na reprodução no cientificismo cartesiano, na fragmentação do conhecimento, na visão do ser humano como centro do universo (antropocentrismo) e sua relação de domínio com o meio natural.

Por outro lado, a EA crítica visa transpor esses elementos e está ligada a transformações de valores sociais, conforme Loureiro (2007). Embora haja essa representação dicotômica da EA, alguns autores, como Sauvé (2005), destacam 16 correntes de EA nas abordagens pedagógicas. Portanto, fala-se em educação ambiental em sua heterogeneidade, compreendida em diferentes enfoques e tipologias.

A produção acadêmica sobre EA desenvolvida nos Programas de Pós-Graduação, no Brasil, no período de 1981 a 2003, foi analisada por Lorenzetti (2008) e esse autor evidenciou a presença de compreensões de EA mais crítico-transformadoras em pesquisadores, enquanto os professores tendem a uma visão ecológica ou de transição. Essa diferenciação repercute também sobre as palavras e expressões recorrentes nas pesquisas, em geral com os professores estabelecendo a EA através de expressões como preservação e conservação de recursos, equilíbrio ecológico, entre outras.

Entre os estudos recentes sobre concepções de EA, podemos destacar as pesquisas com professores de diversas disciplinas (VALENTIN; SANTANA, 2010; WOLLMANN; SOARES; ILHA, 2015), com professores de ciências (CAVALCANTI NETO; AMARAL, 2011; MAKNAMARA, 2009; OLIVEIRA; OBARA; RODRIGUES, 2007), com docentes em formação inicial (CORREIA, 2014; VERONA; LORENCINI JR., 2009), entre outros trabalhos, que se propõem a interpretar o conteúdo, as ambiguidades e finalidades pedagógicas subjacentes ao ideário desses docentes e que parcialmente ajudam a construir a EA escolar. Para isso, os autores analisam o modo de conceber a EA por esses professores e os elementos constituintes de seus projetos e atividades pedagógicas. No bojo dessas pesquisas, são debatidas as concepções tradicionais e acríticas - normalmente ligadas apenas à preservação ambiental e a visões utilitaristas dos recursos naturais - bem como o papel passivo do educando.

\footnotetext{
${ }^{2}$ Evento com participação de diversos chefes de Estado mundiais, que propôs grandes orientações sobre a natureza da EA e definição de seus objetivos e características. Para mais informações sobre essa conferência e reuniões importantes sobre EA, consultar a obra de Dias (2004).
} 
Para além do espaço verde na escola: análise das concepções ...

Além de espaços formais tais como escolas e universidades, outros espaços têm grande relevância como parte da expansão de atividades com temática ambiental no país e vêm assumindo diferentes discursos sobre EA. Podemos destacar o crescimento de feiras e mostras de ciências desde os anos 60, em especial, no Sul e Sudeste do Brasil, como apontam Mancuso e Leite Filho (2006). Atualmente, as feiras e mostras disseminaram-se por todo o país como ações de políticas estaduais, entre as quais destacamos a Feira Estadual de Ciências e Cultura e as Mostras de Educação Ambiental da Rede Estadual de Ensino, no Ceará (MEA).

A MEA é um evento específico para EA que acontece desde 2011 no Estado do Ceará e se estabelece como parte de uma política ambiental da Secretaria de Educação do Ceará (SEDUC). Nesse cenário, na pesquisa desenvolvida ao longo do mestrado ${ }^{3}$, buscamos compreender o modo como professores orientadores que participam da MEA entendem o processo de educação ambiental e consideramos pertinente explicitar as próprias noções e sentidos sobre EA do evento, que, por sua vez, seleciona os trabalhos desses docentes e de seus alunos. Para isso, uma das etapas da pesquisa foi entender qual o entendimento de EA para os organizadores da MEA. Assim, neste artigo, buscamos responder: como se caracteriza a proposta de educação ambiental na Mostra de Educação Ambiental no Ceará?

A resolução deste questionamento implica em compreender o enfoque dado à educação ambiental como cerne do projeto de um evento científico-cultural que realiza a exposição pública de atividades ambientais escolares. Existe um conjunto de investigações dedicadas ao estudo de feiras de ciências (ARAÚJO; CARNEIRO, 2014; BARCELOS; JACOBUCCI; JACOBUCCI, 2010; MANCUSO; LEITE FILHO, 2006), contudo ainda são poucos os trabalhos referentes a eventos específicos sobre EA. Fundamentado em Santos, Carvalho e Levinson (2014), salienta-se que a maior parte dos artigos científicos publicados em revistas nacionais que relacionam educação ambiental e ensino de ciências concentra-se no contexto do ensino fundamental, e entre os temas mais frequentes estão os sentidos de EA a ela atribuídos por professores e alunos, ou, ainda, figuram propostas pedagógicas.

Tal constatação ressalta a carência de pesquisas em espaços pedagógicos não escolares ou com outros níveis de ensino. Desse modo, este trabalho direciona-se a explicitar as características da MEA, que possui como público alvo professores e alunos do ensino médio. Esse evento se apresenta como um momento de culminância do trabalho desenvolvido ao longo do ano nas escolas e foi projetado por formadores ambientais que são responsáveis por coordenar as atividades de educação ambiental na Seduc. Entre as ações desenvolvidas pela MEA, destacam-se as atividades direcionadas à rede estadual de ensino do Estado do Ceará.

Com base em um estudo anterior notamos o papel formativo da MEA, pois ela é representada pelos docentes participantes como espaço de estímulo, de aprendizagem e de compartilhamento de ações (RODRIGUES; LEITE, 2016), o que acentua ainda mais a importância desse evento para a realidade escolar cearense. Logo, torna-se primordial estabelecer as diferentes perspectivas sobre EA, que a constituem. Este artigo tem como objetivo identificar e discutir as concepções sobre educação ambiental presentes na proposta da Mostra de Educação Ambiental da Rede Estadual de Ensino (MEA), no Ceará.

\footnotetext{
${ }^{3}$ Dissertação defendida pelo primeiro autor deste trabalho.
} 


\section{Metodologia}

Investigamos o universo de significados sobre EA na MEA com base na sua construção por seus organizadores e idealizadores. As concepções sobre EA desse grupo social tornam-se mote desta pesquisa, pois nos ajudam a refletir sobre as intenções e compreensões da temática ambiental nesse evento. Por isso, direcionamo-nos para a realização de uma pesquisa de cunho qualitativo, sem uma generalização estatística (MINAYO, 2012), mas com uma imersão no contexto semântico investigado, nesse caso, a compreensão em profundidade de como a EA é representada no evento.

A cidade de Fortaleza foi selecionada como locus desta pesquisa por enviar à fase estadual uma maior quantidade de trabalhos, algo que faz parte da logística do evento. Por isso, foi selecionado um organizador da fase municipal dessa cidade. Também foram selecionados dois organizadores da MEA, que são responsáveis pela fase estadual e que trabalham nessa cidade.

Foram realizadas entrevistas semiestruturadas com organizadores da MEA e coleta de documentos, tais como editais produzidos por esses atores. Os nomes dos sujeitos da pesquisa foram trocados para preservar suas identidades. Para isso, usamos os nomes das letras do alfabeto grego (Quadro 1).

Quadro 1. Perfil dos sujeitos desta investigação

\begin{tabular}{|c|c|l|l|}
\hline Entrevistado & Sexo & \multicolumn{1}{|c|}{ Atividade profissional } & $\begin{array}{c}\text { Tempo como organizador da Mostra } \\
\text { ou participante do evento }\end{array}$ \\
\hline Alfa & F & Técnica educacional da SEDUC & $\begin{array}{l}\text { Organizadora desde o início da mostra } \\
\text { e principal idealizadora }\end{array}$ \\
\hline Beta & F & $\begin{array}{l}\text { Técnica educacional da Superin- } \\
\text { tendência das Escolas Estaduais } \\
\text { de Fortaleza (SEFOR) }\end{array}$ & Organizadora há dois anos \\
\hline Gama & F & Técnica educacional da SEDUC & Organizadora há dois anos \\
\hline
\end{tabular}

Fonte: Elaborado pelos autores.

Com base na Análise de Conteúdo, segundo Bardin (2011), optamos, ao realizar a análise dos editais, por selecionar as principais palavras e expressões que pudessem remeter à ideia de EA dos organizadores e que estão vinculadas à própria EA da MEA. Também utilizamos os critérios de seleção dos trabalhos da MEA como conteúdo latente da compreensão de EA dos organizadores da mostra.

Seguimos as etapas sugeridas por Bardin (2011), tais como a pré-análise do material transcrito e documentos, da qual foi feita uma "leitura flutuante" e organização do material. Após essa etapa, realizamos a exploração do material, a identificação e a segmentação do conteúdo.

Pautados por essa autora, aludida no parágrafo anterior, optamos por realizar análises temáticas (detectar temas que emergiram nos relatos e documentos) e análise de palavras-chave (palavras portadoras de sentidos sobre EA) que estavam presentes nos editais escritos pelos organizadores. Assim, utilizamos como unidades de registro respectivamente temas e palavras, pois segundo Lankshear e Knobel (2008, p. 275): 
Para além do espaço verde na escola: análise das concepções ...

Uma suposição fundamental que está na base da análise de conteúdo é que o uso frequente de determinadas palavras, ou de uma forma específica de expressão, assim como o uso de um determinado vocabulário - ou discurso - transporta informações sobre visões de mundo, ideologias e contextos sociais da época em que o documento foi produzido.

Considerando a perspectiva desses pesquisadores, bem como a de Bauer e Gaskell (2014), que os textos analisados são expressões de seus autores, os editais, ao constituírem o corpus desta pesquisa, contém valores, opiniões, atitudes dos sujeitos da pesquisa que expressam a proposta de EA da MEA. O programa Atlas TI foi utilizado na contagem de palavras das produções escritas dos organizadores e, após a contabilização, essas palavras foram analisadas em seu contexto semântico.

Na próxima seção apresentamos a categoria "Concepções de educação ambiental vinculadas à proposta da MEA", que foi desenvolvida a partir do conteúdo do material investigado. São usadas algumas transcrições representativas das falas dos sujeitos da pesquisa, e optamos por realizar uma descrição inicial dos relatos dos principais idealizadores do evento. Após isto, realizamos a triangulação dos dados das entrevistas com os dados presentes nos documentos. A interpretação dos resultados levou em consideração os estudos sobre educação ambiental feitos por Loureiro (2007) e Guimarães (2004, 2013, 2014), além da tipologia descrita por Sauvé (2005).

\section{Resultados e discussão}

No geral, os organizadores apresentaram concepções diversificadas, que tanto remetem a uma compreensão de EA que questiona o modelo de sociedade em que nos inserimos, quanto a compreensões mais conservadoras de EA.

\section{Noções de educação ambiental que se aproximam da perspectiva crítica}

A organizadora mais antiga da MEA possui uma compreensão de EA em que se destaca uma percepção socioambiental, isto é, de que os problemas ambientais não se instalam apenas de um ponto de vista ecológico (naturalístico), mas que as dimensões sociais repercutem valores da vida moderna, tais como violência e individualismo, e estes são apenas alguns dos aspectos responsáveis pela crise ambiental. Inicialmente, a entrevistada Alfa explica: "Eu entendo EA como um processo em que a gente vai lidar com a relação homem-natureza, mas também com o social. Essa relação homem-natureza não se dá apenas de uma forma física [...]".

Essa compreensão mais crítica das questões socioambientais se opõe a um paradigma de dominação do ser humano sobre a natureza. Como explica Guimarães (2004, p. 26), este paradigma atua criando uma lógica de dominação que separa homem e natureza:

[...] Privilegiando uma dessas partes, o ser humano, sobre as demais, a natureza, estabelece uma diferença hierarquizada que constrói a lógica da dominação. Pela prevalência da parte na compreensão e na ação sobre o mundo, desponta características da vida moderna que são individuais e 
sociais: sectarismo, individualismo, competição exacerbada, desigualdade, espoliação, solidão e violência.

Alfa complementa sua definição de EA e estabelece uma crítica aos slogans verdes de "Preserve a natureza", destacando as relações entre o homem e meio ambiente. Nas palavras de Alfa: "[...] não adianta defender que a natureza seja preservada se eu mesma, dentro de mim, não enxergo o outro, o homem e o meio se complementam".

Por sua vez, os slogans preservacionistas rotineiramente mobilizam professores e educandos no espaço escolar e caracterizam uma EA conservadora. Guimarães (2004) denomina de "armadilha paradigmática" a reprodução em práticas educativas dos paradigmas constituintes da sociedade moderna, tais como o estabelecimento de relações humanas mais frágeis. Essas armadilhas paradigmáticas não são desveladas em práticas com o discurso superficial e preservacionista sobre a dimensão ambiental. Nas palavras desse autor, esses paradigmas são responsáveis pela crise civilizatória: "A violência sinaliza para a perda da afetividade, do amor, da capacidade de se relacionar do um com o outro (social), do um com o mundo (ambiental), denotando a crise socioambiental que é de um modelo de sociedade e seus paradigmas; uma crise civilizatória" (GUIMARÃES, 2004, p. 26).

Dando continuidade a sua definição, Alfa esclarece a importância do respeito à diversidade de saberes, étnica e social, que são valores propagados pelo Programa Nacional Escolas Sustentáveis (PNES) (BRASIL, 2014). Ela destaca também a historicidade das pessoas e aspectos culturais como elementos mais importantes que os slogans de "Preserve a natureza", sinalizando também suas próprias vivências como formadora ambiental na instituição onde trabalha:

[...] eu compreendo que a EA respeita toda diversidade, a diversidade de gênero, a diversidade étnico-racial, a diversidade religiosa e política.

Eu não preciso saber ou pensar como o outro para me dar bem com ele, mas compreender a sua carga histórica e cultural, [...] saber conviver com essas diferenças. Eu acho que a $\mathrm{E} A$ tem esse contexto e, por ter esse contexto, está dentro desta coordenadoria. [Alfa].

Caracteriza a compreensão crítica de EA de Alfa o que Loureiro (2007, p. 69) chama de um "repensar das relações entre eu-eu, eu-outro, eu-nós no mundo", que inter-relaciona natureza-cultura; em que é desvelada a sociedade em suas desigualdades e preconceitos. Portanto, a compreensão desses elementos não se reduz aos saberes das ciências naturais, mas a um movimento dialético entre agir e pensar que cria relações entre saberes diferentes. Alfa sintetiza seu entendimento de EA:

Na nossa visão e na visão do MEC, a EA extrapola essa questão da Ecologia. A gente não quer que a escola tenha apenas um espaço verde. Nós queremos sim que a E $A$ seja voltada para os direitos humanos, para a inclusão. Não adianta ter um espaço físico limpo mas as relações pessoais serem frágeis, en ser uma pessoa externamente preconceituosa no que se refere à religião, à sexualidade e à questão étnico-racial. Temos buscado trabalhar as relações dos nossos jovens diante disso, uma $\mathbf{E A}$ mais completa, complexa no sentido de que abranja esse viés. [Alfa]. 
Como se pode perceber, Alfa possui uma compreensão de EA que busca transformar valores e superar a fragmentação de saberes. Isto é, opõe-se à redução da EA a apenas aspectos ecológicos e à lógica de domínio do homem sobre o meio natural. Segundo Guimarães (2013, 2014), superar essas posturas e matizes da sociedade moderna faz parte de uma nova ética para a humanidade e representa um dos principais postulados da EA, em que se destacam valores e atitudes de cooperação e solidariedade, ou seja, buscam superar relações de dominação entre indivíduos humanos (individualismo), entre saberes (cientificismo) e entre homem-natureza. Essa renovação, na visão do autor, se compromete epistemologicamente à formação de sociedades mais sustentáveis.

Para Gama, outra organizadora que participou de nossa pesquisa, a EA segue também uma linha que busca superar valores, tais como valores consumistas. Sua compreensão de EA relaciona-se a um dos objetivos gerais da EA, conforme Guimarães (2013), que é ampliar a consciência individual do estudante para uma consciência coletiva. Nesse processo, desvela-se tanto a realidade individual (o que se consome) quanto à realidade social (como o consumismo afeta a comunidade):

O maior papel da EA é esta reflexão, às vezes a gente pensa que tem que economizar água, mas não vê uma empresa [agindo] dentro da nossa comunidade de forma devastadora. Então eu acredito que o maior papel que a gente tem aqui é levar esta reflexão ao aluno, éver como o que ele consome [...] e como aquela empresa dentro da comunidade afeta a comunidade dele" [Gama].

Alfa relata sobre como um sistema político-econômico também repercute sobre estruturas sociais e educacionais, ao situar a EA como um grande desafio: "[...] A educação ambiental não é um mote de um país capitalista, contraditório, que tá aí o tempo todo estimulando o consumo. A gente vive no país em que o agronegócio é algo contraditório e vem disfarçado de que é ambientalmente correto". [Alfa].

Esses relatos evidenciam uma noção de que os problemas ambientais manifestam-se com conflitos de interesses, de relações desiguais entre grupos sociais, como estabelece Guimarães:

A educação ambiental crítica das desigualdades sociais e dos desequilíbrios nas relações entre sociedade e natureza percebe os problemas ambientais como decorrentes do conflito entre interesses privados e coletivos, mediados por sua relação desigual e poder que estruturam a sociedade contemporânea em suas múltiplas determinações e seu modo de produção (GUIMARÃES, 2014, p. 75, grifo nosso).

\footnotetext{
${ }^{4}$ A Figura 1 apresenta as dez primeiras palavras que foram registradas mais de dez vezes no corpus analisado. No entanto, as palavras escola, projetos, alunos, professor, participação, diálogo e socialização foram excluídas, apesar de possuírem uma grande frequência, visto que pouco representam a ideia de EA vinculada aos documentos investigados.
} 
A presença de palavras relacionadas à EA nos editais também corrobora esses resultados de elementos que caracterizam uma perspectiva de EA crítica na visão dos principais organizadores. Destacam-se nos editais as palavras e expressões ${ }^{4}:$ meio ambiente, ações, currículo, comunidade, problemas ambientais, sustentabilidade e escola sustentável, que remetem a uma compreensão de EA como um processo contínuo associado ao currículo escolar que, por sua vez, envolvem diversos atores (Figura 1).

Figura 1. Palavras e expressões presentes nos editais relacionadas à concepção de EA dos organizadores

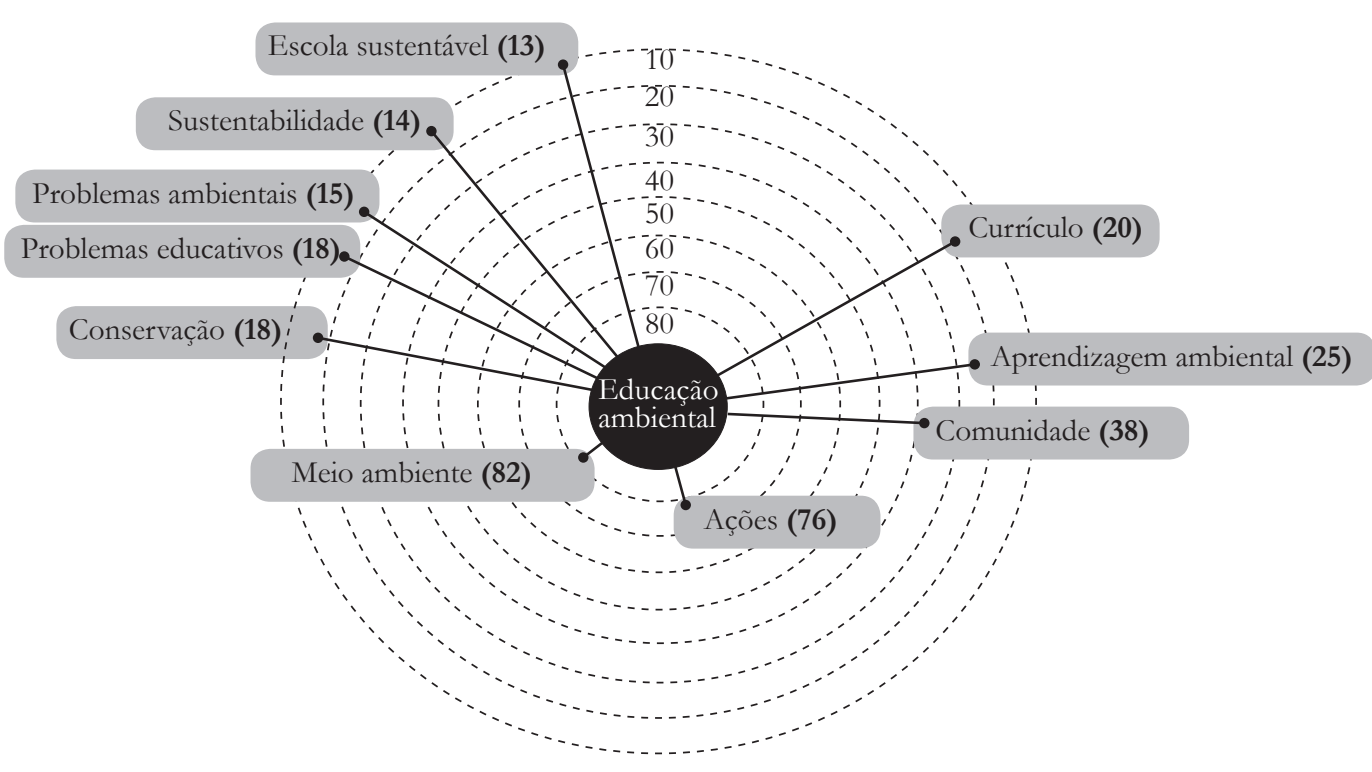

Fonte: Elaborada pelos autores com auxílio do programa Atlas TI ${ }^{5}$

Assim, esta concepção de EA não se restringe a mudanças de comportamento individuais dos alunos, mas envolve ações ambientais coletivas no cotidiano escolar e na comunidade. Lorenzetti (2008) aponta que algumas pesquisas também inserem outras expressões que se aproximam dos pressupostos da EA crítica, tais como os termos abordagem globalizante, visão sistêmica, sociedade sustentáveis, formação do cidadão crítico, participação política, entre outros.

Os critérios de seleção dos trabalhos, mais evidentes e definidos nos últimos editais, distinguem que os trabalhos devem possuir dois tipos básicos de ações, denominados "Ações curriculares" e "Ações educativas" (ver Quadro 2). Essas ações não se situam no campo do

\footnotetext{
${ }^{5}$ Foram selecionadas as dez palavras ou expressões relacionadas à educação ambiental que apresentaram as maiores incidências.
} 
Para além do espaço verde na escola: análise das concepções ...

ativismo ingênuo, mas direcionam-se a compreensão-ação, ao pensar-fazer sobre os problemas ambientais, em diferentes escalas (cotidiano, programa curricular, estrutura física da escola, gestão escolar e comunidade) fundamentadas por abordagem interdisciplinar e contínua na escola, como espaço educador sustentável.

Quadro 2. Critérios usados na seleção dos trabalhos da MEA de 2015

\begin{tabular}{|l|l|}
\hline \multicolumn{1}{|c|}{ Ação curricular } & \multicolumn{1}{c|}{ Ação educativa } \\
\hline $\begin{array}{l}\text { As ações e projetos devem promover a } \\
\text { integração curricular das disciplinas, }\end{array}$ & Ações que promovam as mudanças de atitudes \\
enaltecendo a transdisciplinaridade e & e de comportamentos da comunidade \\
interdisciplinaridade do tema abordado, & escolar e comunidade local quanto à gestão \\
fortalecendo a interface da Educação Ambiental & escolar, currículo e espaço físico que promovam \\
com o cotidiano escolar, de forma permanente & a consolidação das escolas como Espaço \\
ao longo do ano letivo. & Educador Sustentável. \\
\hline
\end{tabular}

Fonte: Adaptado do edital da MEA.

Segundo Oliveira e Tonso (2012), a expressão "Espaço educador" é utilizada no contexto da EA como ação no e para o meio ambiente tanto por escolas quanto por empresas, incrementando esta ideia uma adjetivação de sustentabilidade. Esses autores evidenciam que, de acordo com o contexto, as abordagens pedagógicas são diferentes e podem representar um discurso superficial sobre sustentabilidade que restringe as ações à criação de hortas e espirais de ervas como atividades fins, sem uma reflexão sobre as dimensões social e política.

Os autores destacam como atividades mais recentes que ajudaram a tornar mais evidentes esse conceito o Programa Mais Educação do MEC (2010), que trata da oferta na educação básica em tempo integral e estimula em seu artigo $2^{\circ}$, inciso V, a criação de espaços educadores sustentáveis que busquem a readequação da estrutura física da escola e da gestão escolar, a formação dos professores e a inserção da sustentabilidade no currículo escolar e em materiais didáticos.

Essa nova perspectiva sobre o papel da escola e sustentabilidade influenciou a criação pelo MEC do Programa Escolas Sustentáveis, que têm em seus pilares que as mudanças aconteçam no espaço, no currículo e na gestão da escola. Trajber e Sato (2010) resumem que, nessa proposta, são articulados os saberes científicos, locais e culturais e, nela, são tecidas relações entre atores e contextos da escola, comunidade, bairro e município.

De todo modo, o conceito "Espaço educador sustentável", apesar de não ser explicitamente evidenciado na fala dos entrevistados sobre o que é EA, está incorporado ao conteúdo dos últimos editais produzidos pelos organizadores e refere-se a uma compreensão de escola e

\footnotetext{
${ }^{6} \mathrm{Não}$ pretendemos discutir em profundidade esse conceito, apenas relacioná-lo à concepção de EA dos organizadores. O projeto Escolas Sustentáveis que busca desenvolver a escola como espaço educador sustentável; tem em suas ações a incorporação da comunidade na Com-vida que faz parte de uma proposta governamental nacional em que grupos de alunos e professores são engajados com EA no espaço escolar.
} 
educação com desejos de mudanças em direção à sustentabilidade. Isso se torna mais evidente quando Alfa descreve a MEA e sua relação com sustentabilidade no espaço escolar: "Muita gente ach a que a sustentabilidade é só ter uma horta na escola, economizar água. Muito embora o currículo e o Projeto Político Pedagógico não comtemplem, a ideia é essa: fortalecer".

A entrevistada ainda prossegue:

Dentro desse contexto de escola sustentável, nós temos três eixos [...] seria aquela escola que desenvolve bons espaços físicos, no sentido de ter respeito às condições ambientais, ao patrimônio cultural, à acessibilidade. Ver que o espaço físico não é apenas o verde, é ter uma rampa, ter mobilidade pra se movimentar, um banheiro que acomode o cadeirante, que tenha uma biodiversidade. O outro eixo é o currículo, por que a gente acredita que esta $E A$ que a gente quer tem que sair da sala de aula. Ela não pode ser trabalhada como mudanças de atitudes, apenas, mas ela tem que tá comtemplada nos conteúdos. $O$ professor de Biologia ou de ciências tem que compreender que os outros professores também [são responsáveis por ela]. Não é um privilégio dessas duas formações. Então, a EA tem que ter o saber científico, o currículo tem que ser interdisciplinar e transdisciplinar e, também, ter o saber tradicional. Ela é uma escola sustentável quando tem a gestão, que trabalha [inaudível], a alimentação, se preocupa com a saúde, eficiência, que tenha Com-vidas na escola, eficiência no uso dos seus recursos naturais e respeito aos direitos humanos. Então, pra gente, a escola é sustentável quando acomoda esses três viés [sic]. [Alfa].

Diante deste conteúdo nos editais e falas dessas organizadoras, pode-se perceber que a proposta da MEA dialoga com o Programa Nacional Escolas Sustentáveis (PNES) por meio da ideia de "Escolas sustentáveis" e "Espaço educador sustentável".

Para Menezes e Pereira (2015), ao analisarem o PNES, este representa um grande avanço ao conceber uma cultura de sustentabilidade na escola, com ligações entre a escola, a comunidade e a educação superior, além de ter sido desenvolvido por uma comissão formada por diferentes segmentos da sociedade civil, apesar de limitações nos grupos que conceberam a proposta. Loureiro (2015) também cita esse programa, entre outras políticas federais recentes, como uma proposta fundamentada em uma compreensão de EA crítica.

\section{Aproximações com outras correntes e identidades da educação ambiental}

Embora as principais organizadoras e idealizadoras da MEA tenham essa compreensão mais elaborada sobre sustentabilidade e sobre as práticas educativas relacionadas à EA, observa-se que a organizadora da etapa regional que participou desta investigação apresenta uma perspectiva ainda pouco estruturada que pode se aproximar de uma ótica conservadora de EA, isto é, sem destaque para questões socioambientais, a participação política e a formação para a cidadania crítica, que contesta o modo de produção e valores culturais da sociedade: 
Para além do espaço verde na escola: análise das concepções ...

EA é um processo educativo para o cotidiano para promover a sustentabilidade no planeta e a preservação dos recursos naturais, a sobrevivência do Homem na Terra. [...] Tem que ser trabalhada de forma interdisciplinar, inclusive os professores de português podem estudar sobre desperdício e sustentabilidade. [Beta].

O relato de Beta sugere uma noção de EA reduzida à preservação e à conservação dos recursos naturais e aproxima-se dos resultados de outros estudos, como Oliveira, Obara e Rodrigues (2007) e Wollmann, Soares e Ilha (2015), que se referiram a essa perspectiva de EA como tradicional, simplista e conservacionista. Nessa visão, os recursos naturais são apenas necessários para a manutenção das atividades humanas, para a "sobrevivência do Homem" conforme termo usado por Beta. Desse modo, essa organizadora da MEA estabelece uma compreensão utilitarista em que a natureza é um objeto para o ser humano. Portanto, distancia-se de uma perspectiva de que o ser humano é natureza, de acordo com Guimarães (2004).

Para esse autor, a disjunção entre homem e natureza é que cria uma lógica de dominação, que repercute sobre os valores humanos nas sociedades modernas industriais. Notamos, também, que a fala de Beta estabelece uma concepção de EA que busca romper com as fronteirais disciplinares. Por sua vez, essas compreensões conservacionistas e de relações entre conhecimentos estão presentes nos editais (rever também quadro anterior), como especificado no Quadro 3:

Quadro 3. Critérios conservacionistas e resolutivos usados na seleção dos projetos científicos e culturais

\begin{tabular}{|l|l|}
\hline \multicolumn{1}{|c|}{ Primeiro edital } & \multicolumn{1}{|c|}{ Último edital } \\
\hline $\begin{array}{l}\text { Trabalho/apresentação que contemple uma problemática } \\
\text { ambiental local com apresentação de propostas resolutivas. } \\
\text { Ações que promovam mudanças de atitudes e de } \\
\text { comportamentos da comunidade escolar e comunidade local } \\
\text { quanto à presem }\end{array}$ & $\begin{array}{l}\text { Projeto que contemple uma da preservação e conservação } \\
\text { prol do meio ambiente. } \\
\text { do conservação do meio ambiente. }\end{array}$ \\
\hline
\end{tabular}

Fonte: elaborado pelos autores.

A partir disso, um ponto importante a se mencionar sobre os editais é a presença da expressão projeto científico, que designa os trabalhos enviados ao evento. A palavra "projeto" deriva do latim projectus e significa algo lançado para a frente. Assim, busca tentar tornar real algo novo sem distanciar-se da ação sobre a realidade. Apesar disso, a adjetivação "científico" para designar um dos tipos de trabalhos enviados à mostra dá uma conotação investigativa aos trabalhos, isto é, a MEA tem uma compreensão de EA que valoriza ações ambientais investigativas, assemelhando-se, portanto, à corrente científica de EA relatada por Sauvé (2005). A autora faz uma sistematização de pelo menos 16 correntes - entre as quais a corrente científica - e explica:

Nessa corrente, a educação ambiental está seguidamente associada ao desenvolvimento de conhecimentos e habilidades relativas às ciências do meio ambiente, do campo de pesquisa essencialmente interdisciplinar para a transdisciplinaridade [...] o meio ambiente é objeto de conhecimento para 
escolher uma solução ou uma ação apropriada. As habilidades ligadas à observação e à experimentação são particularmente necessárias (SAUVÉ, 2005, p. 23).

Dessa forma, pode-se dizer que a MEA apresenta uma proposta de EA híbrida, que articula visões conservacionistas, científicas, resolutivas e críticas, com predominância destas últimas, tanto nos relatos quanto nos documentos analisados, a partir da presença dos conceitos relacionados à criação de escolas sustentáveis e por meio do estímulo ao engajamento a transformações sociais e curriculares. Como esta categoria foi elaborada a partir dos relatos dos organizadores e suas produções escritas (regulamentos, critérios da mostra etc.), podemos dizer que essa heterogeneidade sobre EA reflete as intenções desses atores, suas expectativas quanto à mostra como espaço pedagógico. Assim, essas compreensões de EA na MEA são implícitas ao evento. Ou seja, na MEA, convivem compreensões diferentes sobre EA, o que reflete tanto o próprio campo de pesquisa da EA, em suas matizes e correntes, quanto os próprios documentos curriculares nacionais para o Ensino Fundamental (EF) e Ensino Médio (EM), tais como os PCN, conforme Valdanha Neto e Kawasaki (2015).

Com base nesses autores, insistimos que uma padronização dessas visões de EA exaure sua multiplicidade e a possibilidade de criar um processo democrático e dialógico na construção de propostas ambientais, sabendo que a visão crítica é essencial para a transformação social e formação política das pessoas.

Mesmo refletindo esta diversidade sobre EA no Brasil, do ponto de vista histórico da EA, a presença de elementos de uma EA crítica na MEA representa uma ideia reformadora tanto do evento quanto da prospecção de experiências escolares diferenciadas nas escolas da rede estadual do Ceará.

\section{Considerações finais}

Mostramos quais as concepções de EA implícitas na MEA e como se materializa no processo de seleção especificado nos editais. Notamos que a proposta da MEA apresenta elementos diferentes da EA, tais como inserções conservacionistas, científicas, resolutivas e críticas. Assim, não há um discurso uníssono entre seus organizadores e editais. Esse é um reflexo do próprio campo da EA, pois não existe uma EA monolítica. Embora isso aconteça, predomina uma compreensão de EA vinculada a transformações sociais e curriculares, sobre o viés da articulação de disciplinas escolares, da EA contínua e sensível aos problemas ambientais locais.

O referido evento foi inserindo em seus editais ao longo dos anos os conceitos "Escola sustentável" e "Espaço Educador Sustentável”, em busca de experiências comprometidas com visões de sustentabilidade socioambiental na gestão, currículo, espaço físico e comunidade (que representam esses conceitos). Reconhecer essas cosmovisões sobre EA torna-se fundamental diante do investimento e da definição do papel de exposições públicas na área ambiental.

Esta pesquisa não menospreza o trabalho dos organizadores da MEA ao considerar a presença de visões tradicionais de EA como integrante do evento analisado, mas problematiza essas concepções, tendo em vista a importância do evento em âmbito estadual, que é de reconhecer/estimular práticas escolares e, em nível nacional, de ser um evento científico-cultural específico sobre EA, que reflete o campo educacional polissêmico no Brasil. 
Para além do espaço verde na escola: análise das concepções ...

Reiteramos o papel importante que esse evento tem na EA no Estado do Ceará e que iniciativas como essa podem ser adotadas por mais estados brasileiros. Além disso, esses novos eventos específicos para a EA escolar podem dialogar com outras mostras e feiras de EA que existem no Brasil em busca de implementar visões mais críticas que considerem aspectos sociais e políticos como parte dos conflitos ambientais.

Algumas possibilidades de pesquisas futuras emergem deste trabalho, tais como identificar a compreensão de educação ambiental e meio ambiente dos participantes da MEA e relacioná-las com a proposta de EA do evento. Sobre algumas dessas práticas relatadas na mostra e os seus atores (professores orientadores), traremos reflexões em trabalhos posteriores.

\section{Agradecimentos}

Agradecemos aos sujeitos da pesquisa pelo tempo concedido e a colaboração constante com seus conhecimentos sobre a educação ambiental no Ceará, Coordenação de Aperfeiçoamento de Pessoal de Nível Superior (Capes) pela concessão da bolsa de mestrado para o primeiro autor deste trabalho.

\section{Referências}

ARAÚJO, A. V.; CARNEIRO, C. C. B. Abordagem da ciência nas feiras científicas: uma análise dos editais da feira estadual de ciência e cultura do Ceará. In: ENCONTRO NACIONAL DE DIDÁTICAS E PRÁTICAS DE ENSINO, 17., 2014, Fortaleza. Anais... Fortaleza: UECE, 2014.

BARCELOS, N. N. S.; JACOBUCCI, G. B.; JACOBUCCI, D. F. C. Quando o cotidiano pede espaço na escola, o projeto da feira de ciências "vida em sociedade" se concretiza. Ciência \& Educação, Bauru, v. 16, n. 1, p. 215-233, 2010.

BARDIN, L. Análise de conteúdo. Lisboa: Edições 70, 2011.

BAUER, M.; GASKELL, G. (Org.). Pesquisa qualitativa com texto, imagem e som: um manual prático. (12 ed). Petrópolis: Vozes, 2014.

BRASIL. Ministério da Educação. Versão preliminar do Programa Nacional de Escolas Sustentáveis. Brasília, 2014.

CAVALCANTI NETO, A. L. G.; AMARAL, E. M. R. Análise de concepções e visões de professores de ciências sobre educação ambiental. Pesquisa em Educação Ambiental, Rio Claro, v. 6, n. 2, p. 119-136, 2011.

CORREIA, M. M. Concepções de futuras professoras do ensino básico acerca do ambiente, da educação ambiental e das estratégias didáticas em educação ambiental. Ensaio: pesquisa em educação em ciências, Belo Horizonte, v. 16, n. 1, p. 15-29, 2014.

DIAS, G. F. Educação ambiental: princípios e práticas. 9. ed. São Paulo: Gaia, 2004. 
GUIMARÃES, M. Educação ambiental crítica. In: BRASIL. Ministério do Meio Ambiente. Identidades da educação ambiental brasileira. Brasília, 2004.

A dimensão ambiental na educação. Campinas: Papirus, 2013

. A formação de educadores ambientais. Campinas: Papirus, 2014.

LANKSHEAR, C.; KNOBEL, M. Pesquisa pedagógica: do projeto à implementação. Porto Alegre: Artmed, 2008.

LORENZETTTI, L. Estilos de pensamento em educação ambiental: uma análise a partir das dissertações e teses. 2008. 406 f. Tese (Doutorado em Educação Científica e Tecnológica) - Universidade Federal de Santa Catarina, Florianópolis, 2008.

LOUREIRO, C. F. B. Educação ambiental crítica: contribuições e desafios. In: MELLO, S. S.; TRAJBER, R. (Coord.). Vamos cuidar do Brasil: conceitos e práticas em educação ambiental na escola. Brasília: Ministério da Educação, 2007.

. Educação ambiental e educação para o desenvolvimento sustentável: polêmicas, aproximações e distanciamentos. In: LOUREIRO, C. F. B.; LAMOS, R. (Org.). Educação ambiental no contexto escolar: um balanço crítico da década da educação para o desenvolvimento sustentável. Rio de Janeiro: Quartet; Brasília: CNPq, 2015. v. 1, p. 35-67.

LOUREIRO, C. F. B. et al. Conteúdos, gestão e percepção da educação ambiental nas escolas. In: TRAJBER, R.; MENDONÇA, P. R. (Org.). O que fazem as escolas que dizem que fazem educação ambiental? Brasília: Ministério da Educação, 2007. Disponível em: <http://portal.mec.gov.br/dmdocuments/publicacao5.pdf>. Acesso em: 29 jun. 2017.

MAKNAMARA, M. Educação ambiental e ensino de ciências em escolas públicas alagoanas. Contrapontos, Itajaí, v. 9, n. 1, p. 55-64, 2009.

MANCUSO, R.; LEITE FILHO, I. Feiras de ciências no Brasil: uma trajetória de quatro décadas. In: BRASIL. Programa nacional de apoio às feiras de ciências da educação básica: Fenaceb. Brasília: Ministério da Educação, 2006. p. 11-43.

MENEZES, A. K.; PEREIRA, C. S. A contextualização da educação ambiental escolar: uma leitura da dimensão pedagógica dos conflitos ambientais no programa escolas sustentáveis. In: LOUREIRO, C. F. B.; LAMOSA, R. (Org.). Educação ambiental no contexto escolar: um balanço crítico da década da educação para o desenvolvimento sustentável. Rio de Janeiro: Quartet; Brasilia: CNPq, 2015. v. 1, p. 35-67.

MINAYO, M. C. S. (Org.). Pesquisa social: teoria, método e criatividade. 18. ed. Petrópolis: Vozes, 2012.

OLIVEIRA, A. L.; OBARA, A. T.; RODRIGUES, M. A. Educação ambiental: concepções e práticas de professores de ciências do ensino fundamental. Revista Electrónica de Enseñanza de las Ciencias, Vigo, v. 6, n. 3, p. 471-495, 2007.

OLIVEIRA, A.; TONSO, S. Espaço educador: um conceito em formação. In: ENCONTRO NACIONAL DA ANPPAS, 6., 2012, Belém. Anais... Belém: ANPPAS, 2012. p. 1-20.

Disponível em: <http://www.anppas.org.br/encontro6/anais/ARQUIVOS/GT6-393-63320120622220043.pdf>. Acesso em: 12 out. 2015. 
Para além do espaço verde na escola: análise das concepções ...

RODRIGUES, D. A. M; LEITE, R. C. M. Concepções sobre a Mostra de Educação Ambiental no Ceará (MEA): o que dizem organizadores e professores orientadores? In: CARVALHO, M. C. C; CARVALHÊDO, J. L. P. (Org.). Educação e diversidade. Teresina: EDUFPI, 2016.

SANTOS, W. L. P; CARVALHO, L. M; LEVINSON, R. Dimensão política da educação ambiental em investigações de revistas brasileiras de ensino de ciências. Revista Brasileira de Pesquisa em Educação em Ciências, Belo Horizonte, v. 14, n. 2, p. 199-213, 2014.

SAUVÉ, L. Uma cartografia das correntes em educação ambiental. In: SATO, M.;

CARVALHO, I. Educação ambiental: pesquisa e desafios. Porto Alegre: Artmed, 2005.

TRAJBER, R.; SATO, M. Escolas sustentáveis: incubadoras de transformações nas comunidades. Revista Eletrônica do Mestrado em Educação Ambiental, Rio Grande, v. especial, set. 2010.

VALDANHA NETO, D.; KAWASAKI, C. S. A temática ambiental em documentos curriculares nacionais do ensino médio. Ensaio: pesquisa em educação em ciências, Belo Horizonte, v. 17, n. 2, p. 483-499, 2015.

VALENTIN, L.; SANTANA, L. C. Concepções e práticas de educação ambiental de professores de uma escola pública. Ciência \& Educação, Bauru, v. 16, n. 2, p. 387-399, 2010.

VERONA, M. F.; LORENCINI JR., A. Concepções de educação ambiental e a formação inicial de professores de ciências e biologia: uma análise da Universidade Estadual de Londrina (UEL/PR). In: ENCONTRO DE PESQUISA EM EDUCAÇÃO AMBIENTAL, 5., 2009, São Carlos. Anais... São Carlos, SP: UFSCar, 2009.

WOLLMANN, E. M.; SOARES, F. A. A.; ILHA, P. V. As percepções de educação ambiental e meio ambiente de professoras das séries finais e a influência destas em suas práticas docentes. Revista Brasileira de Pesquisa em Educação em Ciências, Belo Horizonte, v. 15, n. 2, p. 387-405, 2015.

Artigo recebido em 13/09/2016. Aceito em 27/01/2017.

Endereço para contato: Universidade Federal do Ceará, Rua Waldery Uchoa, 1 - Benfica - CEP 60020-110, Fortaleza, CE, Brasil. 